\title{
O papel do Ciência Sem Fronteiras na inclusão social: análise interseccional do perfil dos beneficiários do programa na Unicamp
}

\author{
The role of Science Without Borders in social inclusion: \\ intersectional analysis of the profile of program's beneficiaries at Unicamp
}

Rebeca Buzzo Feltrin ${ }^{1}$

Diego Ferreira dos Santos ${ }^{2}$

Lea Maria Leme Strini Velho ${ }^{3}$

Resumo: Nos últimos anos, acompanhamos uma democratização no acesso à universidade pública no país, o que permitiu a entrada de um novo perfil de aluno a esse ambiente antes povoado, quase que exclusivamente, pelos filhos das elites. Apesar deste importante passo em direção à superação das desigualdades sociais, diferenciações internas entre perfis permaneceram, refletindo, dentro das instituições, as desigualdades vivenciadas externamente. Esse artigo analisa o papel do programa Ciência sem Fronteiras na inclusão social de alunos de graduação (ex-bolsistas) da Unicamp, a partir da aplicação de uma metodologia que permitiu traçar o perfil dos beneficiários do programa de maneira interseccional. Os resultados revelam que, embora o programa contemple mecanismos que poderiam favorecer a inclusão social, na Unicamp, o programa continuou beneficiando um perfil muito específico de aluno - homem, branco, oriundo de escola particular no ensino médio, não beneficiário do Programa de Ação Afirmativa para Inclusão Social e sem necessidades especiais. Este também era o perfil mais frequente entre os programas já existentes de mobilidade internacional da instituição. Tais resultados reforçam a ideia de que a superação das desigualdades sociais e marginalidade por esse novo perfil de alunos não termina com o acesso à universidade e que existem outros obstáculos a serem superados.

Palavras-chave: Inclusão social. Interseccionalidade. Mobilidade internacional. 
Abstract: In recent years, there has been a democratization of access to public universities in the country, allowing the appearance of new student profiles in the university environment. Access to the university by members of the lower classes was an important step towards overcoming social inequalities. However, internal differences between students of upper and lower socioeconomic classes still persist, reflecting the inequalities in the broader society. This article focuses on the role of the Science Without Borders program in the social inclusion of undergraduate students (former scholarship holders) from Unicamp, based on the application of a methodology that identified the intersectional profile of the program's beneficiaries. The results indicate that, although Science Without Borders offers mechanisms that allow social inclusion, the main beneficiaries had a very specific student profile - male, white, previous attendees of private high schools, not PAAIS entrants and without special needs. This is precisely the most frequent student profile in the conventional international mobility programs maintained by Unicamp. Such results reinforce the idea that overcoming social inequalities and marginality for this new profile of students does not end with access to university, and that are other obstacles need to be removed.

Keywords: Social inclusion. Intersectionality. International mobility.

\footnotetext{
${ }^{1}$ Universidade Estadual de Campinas | Departamento de Política Científica e Tecnológica | Campinas | SP | Brasil. Contato: rebecafeltrin@gmail.com. ORCID: http://orcid.org/0000-0002-5606-3989

${ }^{2}$ Instituto Federal de Educação, Ciência e Tecnologia de São Paulo | Departamento de Computação | Piracicaba | SP | Brasil. Contato: diegofsantos@ifsp.edu.br. ORCID: http://orcid.org/0000-0002-8304-2665

${ }^{3}$ Universidade Estadual de Campinas | Departamento de Política Científica e Tecnológica | Campinas | SP |

Brasil. Contato: leastrini@gmail.com. ORCID: http://orcid.org/0000-0002-5965-7969
}

- Recebido em: 17 de maio de 2020

- Aprovado em: 4 de novembro de 2020

DOI: http://dx.doi.org/10.1590/S1414-40772021000100016

Este é um artigo publicado em acesso aberto sob uma licença Creative Commons https://creativecommons.org/licenses/by-nc/4.0/ 


\section{Introdução}

O Ciência Sem Fronteiras (CsF) nasceu como um ambicioso programa de internacionalização da Pesquisa e Desenvolvimento (P\&D) brasileiro, centrado na mobilidade internacional de profissionais e pesquisadores em fase de formação acadêmica ou já formados. Seu objetivo era "promover a consolidação, expansão e internacionalização da ciência, tecnologia, inovação e da competitividade brasileira por meio do intercâmbio e da mobilidade internacional"1 em diferentes níveis de formação, além da atração de pesquisadores doutores estrangeiros para o país. A iniciativa foi concebida pelo então Ministério da Ciência, Tecnologia e Inovação (MCTI) e Ministério da Educação (MEC), sendo sua implementação de responsabilidade das agências de fomento - CNPq e Capes - e da antiga Secretaria de Ensino Superior e de Ensino Tecnológico do MEC. O planejamento do programa previa a concessão de 101.000 bolsas de mobilidade internacional, com foco na graduação (78,9\% do total das bolsas) em áreas prioritárias ${ }^{2}$, durante o período de 2012 a $2016^{3}$.

O programa tornou-se um desafio para a Política de Ciência, Tecnologia e Inovação (PCTI) brasileira, tendo em vista a urgente demanda por compreender melhor os instrumentos de internacionalização, além de se estabelecer bases conceituais e empíricas sólidas que permitissem o acompanhamento e a avaliação do programa (VELHO et al., 2013). Portanto, torna-se necessário e relevante o desenvolvimento de estudos que possam responder às demandas apontadas, fornecendo subsídios para orientar as ações de programas de mobilidade internacional no futuro.

Diante disso, essa pesquisa buscou contribuir para a análise dos impactos do CsF em uma importante dimensão que, muitas vezes, não é considerada pelos estudiosos e gestores: a inclusão social. A inclusão social não é explicitamente mencionada como um dos objetivos do CsF, entretanto, alguns mecanismos que incluem o estágio de idiomas para a capacitação dos alunos que não tinham conhecimento prévio da língua do país destino, o pagamento total das taxas escolares cobradas por instituições estrangeiras, a manutenção financeira dos estudantes

\footnotetext{
${ }^{1}$ Disponível em: http://www.cienciasemfronteiras.gov.br/web/csf/o-programa

2 Áreas prioritárias do programa Ciência Sem Fronteiras são: Engenharias e demais áreas tecnológicas; Ciências Exatas e da Terra; Biologia, Ciências Biomédicas e da Saúde; Computação e Tecnologias da Informação; Tecnologia Aeroespacial; Fármacos; Produção Agrícola Sustentável; Petróleo, Gás e Carvão Mineral; Energias Renováveis; Tecnologia Mineral; Biotecnologia; Nanotecnologia e Novos Materiais; Tecnologias de Prevenção e Mitigação de Desastres Naturais; Biodiversidade e Bioprospecção; Ciências do Mar; Indústria Criativa; Novas Tecnologias de Engenharia Construtiva; Formação de Tecnólogos.

${ }^{3}$ Até o encerramento do programa foram implementadas 92.880 , de acordo com dados do Painel de controle do CsF. Disponível em: http://www.cienciasemfronteiras.gov.br/web/csf/painel-de-controle
} 
no exterior, assim como o pagamento das passagens de ida e volta, permitem inferir que o programa, ainda que implicitamente, tenha buscado "internacionalizar com inclusão social". É razoável supor que a adoção de tais benefícios - que não eram oferecidos pelos programas até então existentes - favoreceria a participação de estudantes e de instituições que não eram incluídos nas oportunidades da mobilidade internacional para estudantes de graduação. Entretanto, vale ressaltar que o fato das áreas de artes e humanidades não terem sido contempladas pelo programa pode ter contribuído para a exclusão de diversos alunos de baixa renda, tendo em vista que grande parte dos cursos dessas áreas tende a concentrar alunos oriundos da escola pública, filhos de pais de baixa renda, com pouca ou nenhuma escolaridade, bem como pretos, pardos e indígenas (RISTOFF, 2016). Além disso, a seleção de bolsistas do programa atendeu a critérios estabelecidos localmente pelas instituições de origem e, portanto, não foi alinhada a ações afirmativas. Ainda assim, as particularidades do CsF podem ser vistas como uma oportunidade singular a uma parcela de estudantes brasileiros de baixa renda, cada vez mais presentes no ensino superior, os quais não poderiam bancar tal experiência com recursos próprios ou com o auxílio de suas famílias (VELHO et al., 2013).

Essa pesquisa buscou identificar o papel do CsF na inclusão social de alunos de graduação (ex-bolsistas) da Unicamp, com foco nas seguintes questões: i) o programa foi capaz de reduzir as desigualdades de acesso dos alunos às oportunidades de mobilidade internacional na Unicamp? ii) O capital social e cultural prévio dos alunos influenciaram suas oportunidades de mobilidade internacional?

Para responder a essas questões, esse artigo está estruturado em 4 seções, além desta introdução e das considerações finais. A primeira seção desenvolve o referencial analítico desta pesquisa. Argumenta-se que, a despeito das universidades brasileiras terem se tornado mais diversas em termos do perfil socioeconômico e étnico-racial de seu alunado no período analisado, desigualdades entre os perfis se mantém, devido, especialmente, às diferenças de capital social e cultural entre esses grupos. Em seguida, a seção 2 apresenta o perfil dos alunos de graduação da Unicamp no período estudado (2012-2016). A seção 3 descreve a metodologia construída para a análise interseccional do perfil dos alunos beneficiários do CsF e de bolsas de mobilidade internacional Unicamp. Considera-se tal metodologia uma importante contribuição deste estudo, na medida em que cria o instrumental metodológico que, ao mesmo tempo, define e operacionaliza o que consideramos como "perfil”" dos estudantes. A seção 4 apresenta e analisa os resultados obtidos, com destaque para a participação dos alunos das classes sociais mais desfavorecidas em programas de mobilidade internacional oferecidos pela Unicamp, seguida pelas considerações finais. 


\section{Inclusão social, capital cultural e mobilidade internacional}

O acesso ao ensino superior no Brasil vem se alterando significativamente nas últimas décadas. Foi notável a expansão das oportunidades na educação superior para a população acima de 18 anos, crescendo $161 \%$ no período de 2000 a 20124 (BRASIL, 2015). É possível observar ainda um aumento do acesso de alunos pretos, pardos e indígenas e daqueles entre os $25 \%$ mais pobres, muito embora ainda persistam desigualdades regionais, sociais e econômicas acentuadas (BRASIL, 2015; MOREIRA et al., 2017). A partir da implementação do Sistema de Seleção Unificada (SISU), em 2010, as universidades foram rapidamente se tornando mais diversas: em 2016, praticamente todas as universidades federais (exceto uma), e todos os institutos federais já haviam atingido o mínimo de $50 \%$ de estudantes oriundos da escola pública em todos os seus cursos e turnos (RISTOFF, 2016) ${ }^{5}$. Assim, se antes a universidade pública brasileira era orientada quase que exclusivamente aos filhos de famílias de alta renda e com tempo disponível para o estudo de qualidade (SCHWARTZMAN, 2013), com maior capital social e cultural (MOREIRA et al., 2017) e, em geral, brancos, nos últimos anos, novos perfis de alunos passaram a ter acesso a esse espaço.

Sem dúvida, a inclusão social no ensino superior é um fator crucial para a garantia da cidadania, contribui para a construção de uma sociedade mais igualitária, produtiva e para a promoção da mobilidade social (MOREIRA et al., 2017). Entretanto, essa tendência de democratização do acesso ao ensino superior no país (RISTOFF, 2014; 2016) não ocorreu de forma espontânea. Diversas políticas de ações afirmativas ${ }^{6}$ - orientadas aos grupos tradicionalmente excluídos do ensino superior - foram adotadas pelas universidades públicas

\footnotetext{
${ }^{4}$ Segundo dados do INEP, no período analisado o total de matrículas da população acima de 18 anos subiu de 2.694.245 para 7.037.688. As matrículas em instituições privadas subiram de 1.807.219 para 5.140.312 (aumento de aproximadamente 184\%) e nas instituições públicas, de 887.026 para 1.897.376 (aumento de cerca de $113 \%)$.

${ }^{5} \mathrm{O}$ estudo aponta ainda que das 177.688 vagas ofertadas nas instituições federais em 2015, 82.881 (47\%) foram para estudantes de escola pública, sendo que metade desse montante foi reservada para estudantes pretos, pardos e indígenas.

${ }^{6}$ As políticas de expansão e reestruturação do ensino superior público brasileiro estiveram também focadas, nas últimas décadas, na democratização do acesso de grupos historicamente excluídos. No âmbito federal, podemos citar o Programa de Apoio a Planos de Reestruturação e Expansão das Universidades Federais Brasileiras (REUNI), lançado em 2007, a criação dos Institutos Federais de Educação, Ciência e Tecnologia (IFs), em 2008, o Sistema de Seleção Unificado (SISU), de 2010, o Plano Nacional de Assistência Estudantil (PNAES), de 2010, a Lei de Cotas $n^{\circ}$ 12.711/2012 e a Lei 13.409/2016, que incluiu as pessoas com necessidades especiais ao sistema de cotas. Outras políticas de inclusão foram criadas internamente nas universidades, como é o caso do PAAIS e do PROFIS (Programa de Formação Interdisciplinar Superior), da Unicamp. Considerando também a inclusão social no ensino superior privado, podemos citar iniciativas como o Fundo de Financiamento Estudantil (Fies), criado em 1999 e remodelado em 2010 e o Programa Universidade para Todos (Prouni), de 2005.
} 
estaduais e federais, buscando minimizar os efeitos de privilégios sociais nos processos de acesso à universidade pública brasileira (ALMEIDA; ERNICA, 2015). Apesar disso, o Brasil ainda persiste como um dos países com maior desigualdade na educação, tendo em vista que a renda familiar do indivíduo influencia diretamente no seu acesso ao ensino superior, de tal forma que o efeito da renda supera o efeito da cor/raça no acesso às vagas (MOREIRA et al., 2017). A partir de dados socioeconômicos coletados durante três ciclos do Exame Nacional de Desempenho dos Estudantes - ENADE (2004 a 2012), Ristoff (2016) observou que o perfil de alunos matriculados na grande maioria dos 43 cursos/áreas analisados é mais branco e mais rico do que sua representação na sociedade. Ainda que a participação de alunos de baixa renda e de não-brancos no ensino superior tenha aumentado, ainda está longe de refletir sua real proporção na população brasileira (RISTOFF, 2014; 2016).

Estudos que refletem acerca da diversidade de indivíduos que ingressaram na universidade brasileira nos últimos anos - especialmente a população negra, por seu potencial de transformar o meio universitário - argumentam que:

[...] é preciso refletir acerca do impacto social e do significado da entrada cada vez maior de um contingente populacional que esteve alijado da possibilidade de aceder em grande número à universidade, que, assim, também se configurou como um espaço de reprodução, ampliação e institucionalização do racismo e, por conseguinte, um importante elemento na estruturação, preservação e atualização de um padrão de relações sociais iníquo, pois hierarquizado, discriminatório, excludente e cravado de disposições socioculturais desumanizantes e naturalizadoras (JUNQUEIRA, 2007, p. 18).

Vale ainda destacar que o conceito de diversidade é amplo e deve ir além da ideia de raça, cor, origem étnica ou de pertencimento sociocultural, uma vez que ele se refere às variedades ou variações nas "histórias pregressas de indivíduos e grupos, condições socioeconômicas, trajetórias sociais, status, origens geográficas, deslocamentos territoriais, gênero, orientação afetivo-sexual, visões de mundo, práticas culturais, crenças, religiões etc" Junqueira (2007, p. 19).

Mesmo com um maior acesso ao ensino superior, tais indivíduos acabam tendo que enfrentar novos desafios no decorrer de suas trajetórias acadêmicas. Com o aumento da população escolarizada, há uma propensão de deslocamento das desigualdades sociais para níveis superiores, ou seja, embora as distâncias sociais tenham se reduzido por meio da democratização do acesso ao ensino superior, criam-se novas diferenciações internas, mais sutis, que acabam produzindo "um aumento das clivagens sociais no acesso a certos ramos e fileiras do sistema de ensino" (SEABRA, 2009, p. 85). Isso é evidenciado, por exemplo, quando analisamos as mudanças recentes na composição do alunado por áreas do conhecimento nas 
IES, e fica claro que os cursos de alta demanda e prestígio, que levam a melhores oportunidades e renda no futuro, tiveram pouca ou nenhuma alteração no perfil de seus alunos (RISTOFF, 2014). O perfil dos alunos da área de medicina, por exemplo, se tornou mais rico no período estudado por Ristoff (2014), com cerca de 6 vezes mais estudantes ricos do que a representação correspondente desse grupo na sociedade. Em contraponto, áreas como pedagogia, enfermagem, serviço social e licenciaturas apresentaram um grande contingente de alunos de classes populares, com um perfil mais diverso e mais próximo à realidade da população brasileira. (RISTOFF, 2014; 2016). Assim, mesmo que as desigualdades no acesso à universidade como um todo estejam diminuindo, outras permanecem ou são criadas em seu interior.

De fato, a ampliação do acesso à universidade e até mesmo a formação universitária completa são fatores que contribuem para a mobilidade social dos indivíduos, mas não garantem por si só a igualdade de oportunidades na vida e na carreira. Outras variáveis como, acesso aos saberes e modo de vida dos grupos dominantes, o conhecimento de idiomas estrangeiros, as experiências no exterior, entre outras oportunidades extras adquiridas fora do ambiente acadêmico/escolar - aquilo que Bourdieu (2007) chama de capital cultural - podem facilitar ou barrar o acesso dos indivíduos a certas oportunidades na vida. Embora a formação universitária seja considerada por Bourdieu como uma forma de capital cultural (na forma institucionalizada), as outras dimensões do capital cultural (incorporado e objetivado) são fundamentais para o sucesso escolar/acadêmico do indivíduo, já que os três tipos de capital cultural são interdependentes ${ }^{7}$. O capital cultural, de acordo com Bourdieu (2007), é adquirido e facilitado pelas oportunidades proporcionadas desde a infância, transmitido prioritariamente no seio familiar, e podem promover a mobilidade social do indivíduo.

A ideia de que a socialização familiar reflete o habitus, fornecendo todo um contexto socializador do gosto e das preferências construídos através das relações de participação

\footnotetext{
${ }^{7} \mathrm{O}$ capital cultural incorporado trata-se do conhecimento e familiaridade a um modo de viver e ver o mundo, ou seja, um enraizamento dos valores (bens simbólicos) no pensamento do indivíduo. O capital cultural objetivado refere-se à propriedade de bens simbólicos (obras de arte, instrumentos científicos, etc) que podem ser convertidos em lucro ou vantagem (embora só seja possível desfrutar do bem em questão a partir da posse do capital cultural incorporado). Já o capital cultural institucionalizado, que se trata do reconhecimento formal de uma instituição do conhecimento do indivíduo em alguma área (acadêmica ou profissional), embora possa ser adquirido (atualmente) por indivíduos de diferentes classes sociais, para os filhos das elites o caminho até à universidade é quase 'natural'. Além disso, os outros dois tipos de capital cultural são determinantes para o sucesso acadêmico/escolar do indivíduo (tanto pela posse de materiais e instrumentos que possam facilitar a aquisição de novos conhecimentos, quanto pela sua familiaridade com a linguagem e modo de ver o mundo, já que o saber reconhecido e institucionalizado é alinhado ao saber das classes dominantes).
} 
estabelecidas com a cultura desde a infância, tem sido defendida por Bourdieu e seus seguidores. A educação escolar, por sua vez, tende a reproduzir e perpetuar a visão de mundo e modos de vida das elites (BOURDIEU; PASSERON, 1975). A participação cultural vivenciada ao longo da vida é vista como uma consequência direta da socialização vivenciada na infância e reflete as desigualdades existentes no início da vida dos indivíduos, fazendo com que crianças oriundas de classes sociais superiores estejam sempre culturalmente mais avançadas e obtenham, mais facilmente, sucesso escolar (BARBOSA, 2016).

De fato, não se pode ignorar que os alunos oriundos de classes sociais mais elevadas acabam levando vantagem e tendo acesso a oportunidades extras durante o período de graduação, seja na assimilação de conteúdos no momento de seleção para uma vaga de emprego ou na seleção para bolsas de intercâmbio, reforçando a ideia de que o capital cultural contribui diretamente para o "sucesso" acadêmico e profissional do indivíduo (DIMAGGIO, 1982). Desta forma, mesmo que duas pessoas percorram a mesma trajetória acadêmica, no mesmo período e instituição, as oportunidades oferecidas a ambos e o acesso a determinados espaços seriam diferentes.

A visão de Bourdieu e Passeron (1975) sobre o sistema educacional e a ação pedagógica, entretanto, não está livre de contestações. Saviani (2008), por exemplo, critica a tese de que a educação seria uma mera reprodutora das desigualdades sociais que reforça a marginalidade dos dominados ao invés de superá-la, colocando a resistência ou a revolução como inatingíveis para a classe dominada e esvaziando a força transformadora da ação pedagógica. Neste sentido, Saviani (2008, p. 24-25) alerta que não podemos sacrificar a história "na reificação da estrutura social em que as contradições ficam aprisionadas", mas devemos olhar para a escola - e podemos estender também às instituições de ensino superior - como uma realidade histórica, ou seja, com a possibilidade de ser "transformada intencionalmente pela ação humana".

Pensando na possibilidade de articular uma instituição de ensino a partir dos interesses dos dominados, ou seja, organizá-la como um instrumento capaz de contribuir para a superação da marginalidade, Savianni desenvolve sua teoria crítica da educação e reforça:

\footnotetext{
Lutar contra a marginalidade por meio da escola significa engajar-se no esforço para garantir aos trabalhadores um ensino da melhor qualidade possível nas condições históricas atuais. O papel de uma teoria crítica da educação é dar substância concreta a essa bandeira de luta de modo a evitar que ela seja apropriada e articulada com os interesses dominantes (p. 26).
}

Saviani (2008) defende, ainda, que deve haver um fortalecimento dos conteúdos culturais transmitidos através da educação, especialmente às classes dominadas, porque: 
o domínio da cultura constitui instrumento indispensável para a participação política das massas. Se os membros das camadas populares não dominam os conteúdos culturais, eles não podem fazer valer os seus interesses, porque ficam desarmados contra os dominadores, que se servem exatamente desses conteúdos culturais para legitimar e consolidar a sua dominação. [...] o dominado não se liberta se ele não vier a dominar aquilo que os dominantes dominam. Então, dominar o que os dominantes dominam é condição de libertação. [p. 45].

Ampliar o conhecimento da cultura aos dominados, como proposto por Saviani, poderia ter efeitos, inclusive, no desempenho universitário e profissional dos alunos, já que - conforme aponta Bourdieu (2007) - os conteúdos culturais reconhecidos e institucionalizados advéem da classe dominante. Por outro lado, não se trata de transformar o dominado em dominador ou o oprimido em opressor, através da aquisição de conhecimentos culturais socialmente reconhecidos como válidos. O domínio da cultura daria aos dominados uma possibilidade de conhecer as regras do jogo - ou habitus do campo (BOURDIEU, 2007) - e, só assim, poderia ter voz ativa, reconhecimento nos espaços de negociação e se tornar agente para a transformação da realidade social.

Neste mesmo sentido, DiMaggio (1982) reforça a importância da aquisição de conteúdos culturais para a superação das desigualdades sociais e argumenta que o capital cultural pode ser adquirido com êxito em outros períodos da vida, contrariando a visão de Bourdieu e Passeron (1975) de que as oportunidades na infância seriam as principais determinantes da trajetória do indivíduo.

O modelo de mobilidade cultural de DiMaggio (1982) propõe que a participação dos indivíduos em determinados espaços e experiências (como é o caso do acesso às artes e cultura), mesmo que seja posterior à socialização primária, pode levar à mobilidade cultural e, consequentemente, facilitar a mobilidade social (BARBOSA, 2016; DIMAGGIO, 1982). Para o autor, a influência da escolaridade dos pais sobre as oportunidades escolares do indivíduo, por exemplo, vai diminuindo ao longo do percurso escolar do próprio indivíduo, ou seja, em um dado momento, seu capital cultural e experiências de vida assumem o protagonismo (DIMAGGIO, 1982; BARBOSA, 2016). Assim, a socialização escolar - nos seus diferentes níveis - seria um contexto privilegiado para a criação de hábitos de participação cultural, possibilitando influenciar diretamente o comportamento dos indivíduos no decorrer da vida, através da ação do ensino e da aprendizagem (DIMAGGIO; USEEM, 1980 apud BARBOSA, 2016).

A partir desse debate, é possível inferir sobre as potencialidades dos programas de mobilidade internacional para a construção de capital cultural dos novos perfis de indivíduos que ingressaram na universidade brasileira. A experiência de mobilidade internacional poderia 
ser uma oportunidade única de fornecer a esses alunos parte desse capital cultural que não foi adquirido no âmbito familiar ou mesmo na sua vida escolar inicial e que seriam instrumentais para a superação de sua condição de marginalidade. A participação em programas de mobilidade internacional e, consequentemente, o contato com novos conteúdos culturais que não seriam experimentados de outra forma pelos alunos, poderiam contribuir para a redução das desigualdades de oportunidades durante e após a formação universitária entre os alunos oriundos de diferentes realidades sociais.

Por outro lado, temos que considerar algumas particularidades e contradições do processo de internacionalização do ensino superior. A participação de uma universidade em um sistema global de ensino pode trazer inúmeros benefícios - tanto para a instituição, quanto para a formação estudantil - mas também traz consigo diversos riscos decorrentes da competição globalizada em busca de prestígio e retornos econômicos (NEVES; BARBOSA, 2020). Este processo pode ainda favorecer a manutenção e invisibilização de desigualdades sociais, a hegemonia da língua inglesa, além da perpetuação de diferenças que favorecem sistemas de ensino superior de países desenvolvidos, como é o caso dos EUA (MARGINSON, 2007 apud NEVES; BARBOSA, 2020). Além disso, conforme ponderam Khomyakov et al. (2020), a orientação neoliberal da internacionalização transforma o conhecimento em produto que pode ser negociado. Os autores analisam que, para atraírem alunos estrangeiros, as universidades devem estar alinhadas a um modelo de global de ensino e galgar espaços nos rankings acadêmicos, o que pode ser custoso (financeiramente e organizacionalmente) para as instituições de países em desenvolvimento (KHOMYAKOV et al., 2020). Assim, pelo fato das instituições alocadas em países desenvolvidos (EUA e Europa) estarem mais bem posicionadas nos rankings, elas acabam recebendo mais alunos estrangeiros - em geral, oriundos do sul global - os quais pagam altas taxas escolares e geram receitas para que tais instituições se mantenham em nível de excelência (KHOMYAKOV et al., 2020).

A busca empreendida pelas universidades em atrair "alunos de excelência", geralmente oriundos de classes sociais mais altas e maior capital cultural e social, contraria também a visão de inclusão social e massificação do ensino superior. Neste sentido, KHOMYAKOV et al. (2020) recomendam que as alternativas de colaboração sul-sul devam ser consideradas pelas instituições, buscando o mútuo apoio no desenvolvimento econômico e social dos países envolvidos. Por outro lado, mesmo diante das críticas e riscos associados à internacionalização, esse processo poderia favorecer aos alunos uma mudança de valores e visões críticas sobre o sistema universitário estimulada pela participação em discussões globalizadas - e podemos incluir, pelas vivências interculturais - possibilitando uma maior conscientização e 
entendimento de conceitos como, por exemplo, de dominação e marginalização no ensino superior (WALKER, 2009 apud NEVES; BARBOSA, 2020).

Lee (2012) reforça a visão de que os alunos historicamente marginalizados devam ocupar novos espaços e buscar oportunidades dentro da universidade, sem que tenham que renunciar às próprias raízes ou embranquecer suas origens, mas trazê-las consigo para transformar tais instituições "que reforçam as hierarquias opressivas em instituições que derrubam essas hierarquias". A autora defende ainda que esses alunos podem mudar a composição interna da instituição ao permanecerem e trazerem seus pares consigo e, assim, conseguirem participar ativamente das decisões, redefinindo e questionando os valores que estão em jogo. A universidade, mesmo com todas as suas contradições, ainda é o melhor espaço para semear mudanças, já que é um local socialmente legitimado de produção e reprodução de conhecimento, mas também de valores e crenças, e suas transformações internas podem ressoar para toda a sociedade (LEE, 2012).

Ancorados nos debates apresentados até aqui, partimos, então para a exploração empírica sobre as questões levantadas sobre a dimensão da inclusão social do CsF no contexto da Unicamp. O primeiro passo é apresentar os perfis do alunado de graduação desta universidade entre os anos 2012 e 2016, período no qual o programa de mobilidade internacional CsF foi implementado.

\section{Perfil dos alunos de graduação da Unicamp durante o CsF (2012-2016)}

Embora não tenha aderido ao modelo de reserva de vagas, a Universidade Estadual de Campinas - assim como outras universidades paulistas - adotou um modelo de acréscimo de notas do vestibular, o Programa de Ação Afirmativa e Inclusão Social (PAAIS), considerando o perfil socioeconômico e étnico-racial do aluno (ALMEIDA; ERNICA, 2015). Essa estratégia contribuiu para uma mudança gradativa nas características - especialmente aquelas ligadas às variáveis de cor/raça, origem de escola do ensino médio e renda familiar - dos estudantes da universidade. De acordo com dados da Comissão Permanente para os Vestibulares (Comvest) no período de 2012 a $2016^{8}$ (Quadro 1), o número de alunos autodeclarados brancos caiu de $76,7 \%$ em 2012, para $68,6 \%$ em 2016, enquanto o número de pretos e pardos aumentou no mesmo período (pretos, $2,8 \%$ para $4 \%$ e pardos, $12,3 \%$ para $18,2 \%$ ).

\footnotetext{
${ }^{8}$ Disponível em: http://www.comvest.unicamp.br/estatisticas-comvest/vestibulares/vestibulares-anteriores/
} 
Quadro 1 - Alunos ingressantes na graduação da Unicamp, segundo cor/raça declarada (2012-2016)

\begin{tabular}{|c|c|c|c|c|c|c|c|c|c|c|}
\hline \multirow[b]{2}{*}{ Cor ou raça declarada } & \multicolumn{2}{|c|}{2012} & \multicolumn{2}{|c|}{2013} & \multicolumn{2}{|c|}{2014} & \multicolumn{2}{|c|}{2015} & \multicolumn{2}{|c|}{2016} \\
\hline & \# & $\%$ & \# & $\%$ & $\#$ & $\%$ & \# & $\%$ & \# & $\%$ \\
\hline Branca & 2.726 & 76,7 & 2.707 & 77 & 2.591 & 72,8 & 2.461 & 74,4 & 2.224 & 68,6 \\
\hline Preta & 101 & 2,8 & 87 & 2,5 & 134 & 3,8 & 76 & 2,3 & 129 & 4 \\
\hline Parda & 437 & 12,3 & 366 & 10,4 & 493 & 13,9 & 435 & 13,2 & 590 & 18,2 \\
\hline Amarela & 197 & 5,5 & 186 & 5,3 & 172 & 4,8 & 179 & 5,4 & 161 & 5 \\
\hline Indígena & 7 & 0,2 & 10 & 0,3 & 7 & 0,2 & 7 & 0,2 & 7 & 0,2 \\
\hline em branco & 86 & 2,4 & 66 & 1,9 & 67 & 1,9 & 55 & 1,7 & 54 & 1,7 \\
\hline Não declarada & & & 95 & 2,7 & 95 & 2,7 & 93 & 2,8 & 78 & 2,4 \\
\hline
\end{tabular}

Fonte: construção própria a partir de dados da Comvest.

Além disso, o número de alunos que cursaram todo o ensino médio em escola particular caiu de $60,8 \%$ para $47,7 \%$, enquanto o número de alunos que cursaram todo o ensino médio em escola pública subiu de $31,6 \%$ para $47,4 \%$, atingindo a paridade com o primeiro grupo, conforme Quadro 2.

Quadro 2 - Alunos ingressantes na graduação da Unicamp, segundo natureza do Ensino Médio (20122016)

\begin{tabular}{|c|c|c|c|c|c|c|c|c|c|c|}
\hline \multirow[b]{2}{*}{ Ensino Médio - Origem } & \multicolumn{2}{|c|}{2012} & \multicolumn{2}{|c|}{2013} & \multicolumn{2}{|c|}{2014} & \multicolumn{2}{|c|}{2015} & \multicolumn{2}{|c|}{2016} \\
\hline & \# & $\%$ & \# & $\%$ & \# & $\%$ & \# & $\%$ & $\#$ & $\%$ \\
\hline Particular & 2.160 & 60,8 & 2.147 & 61,1 & 2.001 & 56,2 & 2.091 & 63,3 & 1.548 & 47,7 \\
\hline Público & 1.123 & 31,6 & 1.080 & 30,7 & 1.302 & 36,6 & 997 & 30,2 & 1.537 & 47,4 \\
\hline Mais Público & 56 & 1,6 & 57 & 1,6 & 47 & 1,3 & 42 & 1,3 & 31 & 1 \\
\hline Mais Particular & 87 & 2,5 & 110 & 3,1 & 96 & 2,7 & 85 & 2,6 & 45 & 1,4 \\
\hline Particular/Público & 5 & 0,1 & & & & & & & & \\
\hline Outro & 5 & 0,1 & 5 & 0,1 & 16 & 0,5 & 14 & 0,4 & 6 & 0,2 \\
\hline Em branco & 118 & 3,3 & 113 & 3,2 & 93 & 2,6 & 70 & 2,1 & 71 & 2,2 \\
\hline No exterior & & & 5 & 0,1 & 4 & 0,1 & 7 & 0,2 & 5 & 0,2 \\
\hline
\end{tabular}

Fonte: construção própria a partir de dados da Comvest.

Os alunos com renda familiar até 3 Salários Mínimos (SM) passaram de 11,9\% dos ingressantes em 2012 para 18,8\% em 2016, enquanto aqueles com renda familiar superior a 20 SM tiveram sua participação reduzida de $4,8 \%$ para $2,3 \%$. O alunado com renda familiar até 5 SM cresceu significativamente de $27 \%$ em 2012 para $41 \%$ em 2016.

O monitoramento contínuo realizado pela Comvest entre os ingressantes da Unicamp vem mostrando que, mesmo que esses alunos bonificados pelo PAAIS obtenham uma nota 
menor no vestibular ${ }^{9}$, no decorrer da vida acadêmica eles superam essas diferenças e passam a apresentar um desempenho igual ou superior àquele dos alunos que ingressaram na universidade sem auxílio do programa (UNICAMP, 2017). Para efeito de comparação, entre 2012 e 2015, considerando apenas as áreas prioritárias do CsF, o desempenho dos alunos bonificados pelo PAAIS se igualou ao dos não bonificados nas áreas de Biológicas e Saúde, Engenharias e Medicina, além de superar o Coeficiente de Rendimento (CR) dos não bonificados nas áreas Tecnológicas. Apenas na área de Exatas (excluindo-se as tecnológicas), o CR dos não bonificados ultrapassou o dos alunos do PAAIS ${ }^{10}$. Tal análise parece indicar que as barreiras mais difíceis de serem superadas pelos alunos de classes sociais mais baixas da Unicamp não são aquelas ligadas ao conhecimento técnico-científico, mas sim aquelas de ordem sociocultural.

Foi precisamente nesse período de início da diversificação socioeconômica e étnicoracial do alunado da Unicamp, que o programa CsF foi implementado.

A experiência do CsF na mobilidade estudantil brasileira foi singular. A grande oferta de bolsas centrada na mobilidade internacional de alunos de graduação, ações como o Idiomas sem Fronteiras, o pagamento total pelo programa de taxas escolares em universidades no exterior, o custeio total das passagens e demais recursos para a manutenção do estudante no exterior, o critério de seleção centrado na instituição de origem, entre outras particularidades do programa, favoreceram a entrada de novos atores (tanto estudantes, quanto instituições) no cenário da mobilidade internacional no Brasil.

Dadas as características apontadas, é razoável esperar que o programa $\mathrm{CsF}$ tenha favorecido a democratização do acesso às oportunidades de bolsas de mobilidade internacional no Brasil. Em geral, os outros programas ${ }^{11}$ de bolsas de mobilidade internacional anteriores ao CsF requeriam um conhecimento prévio avançado do idioma do país de destino - experiência em geral financiada pela família dos estudantes - condição que, dificilmente, poderia ser

\footnotetext{
${ }^{9}$ Bourdieu, ao analisar o sistema de seleção escolar, conclui que ele é desenhado para manter a ordem social vigente e, portanto, tem por objetivo separar alunos dotados de quantidades desiguais de capital cultural (justificado por uma ideia de meritocracia). As universidades - como geradoras de capital cultural - poderiam facilitar a ascensão social dos mais pobres, entretanto, desde a seleção esse sistema é excludente e dificulta o acesso dos mais pobres e, posteriormente, sua permanência no ensino superior, tendo em vista que as visões de mundo e até a linguagem utilizadas são distantes de sua realidade social.

10 Ver em: http://g1.globo.com/sp/campinas-regiao/noticia/2017/03/aluno-da-rede-publica-e-recuperado-nagraduacao-diz-estudo-da-unicamp.html

11 Esses outros programas de mobilidade correspondem, basicamente, aos convênios de cooperação entre universidades brasileiras e estrangeiras que permitiam aos alunos cursarem disciplinas isoladas de graduação por um período determinado.
} 
atendida pelos estudantes de classes sociais mais baixas através da realização de cursos de idiomas no país com baixa periodicidade. Além disso, as taxas escolares e despesas extras decorrentes do intercâmbio eram, em geral, custeadas pelas famílias dos alunos. As outras bolsas de mobilidade eram, portanto, extremamente seletivas, buscando atender um perfil de aluno muito particular, com uma bagagem prévia de capital social, cultural e econômico.

Vale lembrar que os ganhos de uma experiência de mobilidade internacional não se restringem ao treinamento técnico-científico, possibilitam a incorporação de capital cultural (contato com novo idioma, artes, costumes, etc.) e de capital social (criação de redes de contato influente no mundo acadêmico e profissional, como pesquisadores, grandes empresas, etc) que são tão ou mais importantes para o graduando quanto o próprio treinamento acadêmico, especialmente aos alunos que não tiveram acesso anterior à oportunidades correlatas. De fato, um estudo realizado sobre os alunos britânicos de graduação dos anos 2015 a 2016 evidenciou que aqueles que tiveram uma experiência internacional via programa Erasmus ${ }^{12}$ conseguiram obter empregos com salários mais altos do que aqueles que não tiveram essa experiência. Mais importante, entretanto, foi o achado de que o impacto para aqueles alunos que vinham das classes sociais mais baixas foi significativamente maior do que para os de classes sociais privilegiadas (UUKI, 2018).

Neste sentido, a análise do perfil dos alunos contemplados pelo CsF na Unicamp através de uma metodologia interseccional poderá auxiliar na compreensão dos efeitos do programa na inclusão social.

\section{Metodologia de análise de perfil a partir da abordagem interseccional}

A abordagem interseccional surgiu a partir das necessidades identificadas pelas feministas negras norte-americanas, que criticavam o posicionamento dos grupos "feministas" no país que se estruturavam a partir das demandas de mulheres brancas e de classes sociais mais altas. Desde o início, a abordagem interseccional se propunha ir além da reflexão teórica sobre as desigualdades sociais, estando sempre orientada ao campo da intervenção política. Crenshaw (2002) explica a metáfora da intersecção como sendo ligada ao cruzamento de estradas, onde se localizam as pessoas num lugar associado a sistemas múltiplos de subordinação. Para tanto,

\footnotetext{
${ }^{12} \mathrm{O}$ Erasmus (agora em uma nova edição, Erasmus Plus) é um programa europeu de cooperação internacional que promove a mobilidade internacional, especialmente entre estudantes de graduação. Disponível em: https://ec.europa.eu/programmes/erasmus-plus/node_pt
} 
é fundamental para a análise interseccional "buscar capturar as consequências estruturais e dinâmicas da interação entre dois ou mais eixos" (CRENSHAW, 2002, p. 177). Tais eixos, segundo elas, não agem isoladamente, o que leva à necessidade de adotar uma perspectiva que considere uma multiplicidade de fatores que condizem a situações de exclusão e que ofereça uma visão mais ampla e sensível para explicar as complexidades sociais (McCALL, 2005).

Para a abordagem interseccional, o foco é a compreensão de diferentes formas de desigualdade e exclusão social, identificando quais conceitos ou marcadores sociais da diferença (MOUTINHO, 2014) são acionados na configuração das desigualdades em determinado contexto. Embora haja uma discussão teórica robusta sobre a interseccionalidade, a discussão metodológica sobre como operacionalizar tais conceitos está muito aquém do esperado.

A metodologia aqui apresentada, concebida a partir dessas teorias, orientou o desenvolvimento de um software denominado AIP - Análise Interseccional de Perfil. O software, desenvolvido em Java, tem a finalidade de operacionalizar os marcadores sociais da diferença de forma interseccional, ou seja, busca ampliar a visão sobre as desigualdades sociais e como operam as diferentes formas de exclusão, fugindo da visão simplista focada em apenas uma única categoria, variável ou dimensão, como sexo, cor/raça ou classe social. O objetivo é se aproximar do entendimento de como esses marcadores sociais operam em conjunto e, assim, apreender a complexidade das múltiplas identidades dos indivíduos.

O conceito de "perfil interseccional" foi concebido nesta pesquisa para dar conta da análise dessas diferentes dimensões, categorias ou variáveis de forma conjugada. Longe de pretender reduzir os indivíduos a categorias fixas, o objetivo da análise é apreender os múltiplos fatores que operam de maneira combinada na geração das desigualdades sociais. Desta forma, o perfil pode ser composto por diferentes variáveis/categorias, a depender da análise pretendida. No caso deste estudo, as variáveis escolhidas para compor os perfis foram: sexo, cor/raça, necessidades especiais, beneficiário do PAAIS, natureza da escola do ensino médio ${ }^{13}$. $\mathrm{O}$ conceito de perfil é útil nessa compreensão, uma vez que parece haver um "tipo" ou "perfil" ideal para ocupar determinados espaços privilegiados e, quanto mais os indivíduos se aproximam desse ideal, mais chances têm de obter sucesso.

\footnotetext{
${ }^{13}$ As variáveis selecionadas são relevantes para a compreensão das desigualdades e formas de exclusão sociais. Enquanto as duas primeiras são marcadores sociais da diferença tradicionalmente analisados pelos estudos interseccionais, a variável "necessidades especiais" costuma ser utilizada nas análises sobre inclusão social. Já as duas últimas variáveis foram utilizadas nesse estudo para compor um indicador de nível socioeconômico do aluno.
} 
A Figura 1 apresenta a tela principal do software AIP já com os dados carregados e perfis gerados a partir de um conjunto de variáveis selecionadas. O programa é capaz de ler e analisar dados desagregados dos indivíduos (sexo, cor/raça, idade, entre outros), armazenados em arquivo formato Excel®. Após a análise do arquivo, o software identifica, automaticamente, as categorias (através do rótulo das colunas da planilha) e as apresenta para o usuário (painel Group By). O usuário seleciona as categorias que deseja (nesse exemplo foram selecionadas as categorias sexo, raça, PAAIS, natureza da instituição e nome do curso) e o software agrupa os perfis idênticos para possibilitar uma análise quantitativa. Por fim, contabiliza cada um dos perfis idênticos (grupos) - do mais frequente para o menos frequente em cada dimensão analisada e apresenta a porcentagem que cada um desses perfis representa no total de indivíduos analisados.

Figura 1 - Tela principal do software AIP

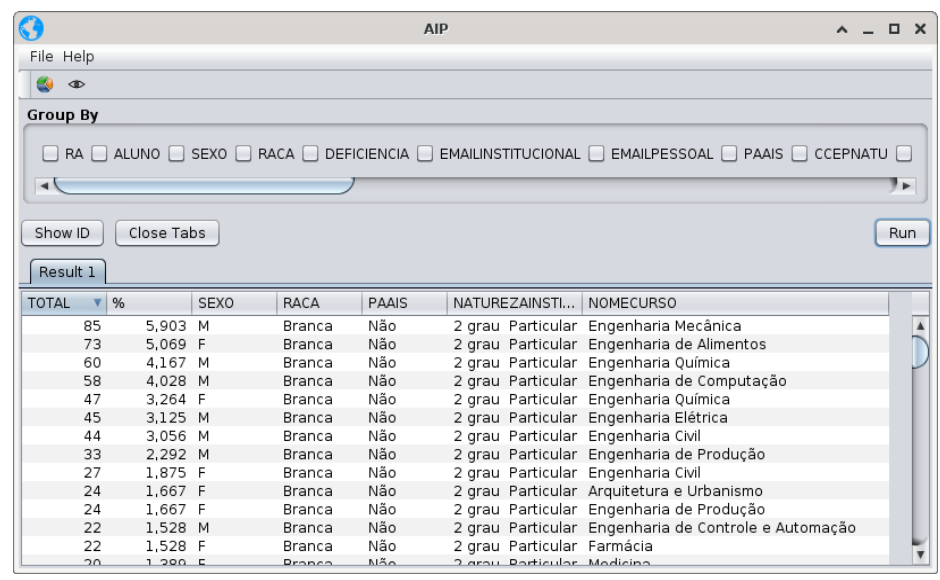

Fonte: Imagem do software AIP gerada pelos autores

O software possibilita, ainda, aplicar filtros internos nos dados gerados, exportar os resultados para uma planilha e gerar gráficos em barra e em formato pizza para os perfis selecionados pelo usuário.

A análise do perfil nos possibilita entender como as variáveis se comportam conjuntamente: por exemplo, não somente analisa quantas mulheres participam do CsF, mas dá um retrato mais realista de "quais" mulheres são incluídas, já que elas não formam um grupo homogêneo. O software AIP, portanto, implementou a metodologia desenvolvida na pesquisa e possibilitou a operacionalização das variáveis e seu agrupamento por perfil de maneira rápida e automatizada.

A abordagem interseccional é bastante utilizada para a análise das desigualdades sociais, embora alguns autores apontem limitações. Kergoat (2010), por exemplo, critica a metodologia interseccional, recorrendo ao conceito de consubstancialidade para advertir que não se deve 
concentrar nas variáveis e seus intercruzamentos, mas deve-se ir além e focar nas relações sociais que estão em jogo, compreender o seu contexto histórico, além de considerar tais categorias como mutáveis (CHO et al., 2013; HIRATA, 2014). Para a autora, fechar os grupos em categorias fixas e estáticas pode contribuir para a reprodução das desigualdades sociais ao invés de combatê-las. Outra crítica apontada por Kergoat (2010) é de que a metodologia interseccional é muito mais centrada nos marcadores de sexo e raça (fruto de sua origem com as black feminists norte-americanas) e menos em sexo e classe social. Para ela, classe social e raça são interdependentes. Por outro lado, mesmo com tais limitações, a interseccionalidade continua sendo reconhecida como uma poderosa ferramenta analítica-metodológica para as ciências sociais.

Diante disso, o conceito de perfil interseccional parece dar conta da recomendação em não dar peso a cruzamentos ou relações específicas, como em sexo-raça (foco da interseccionalidade) ou em sexo-classe (foco da consubstancialidade). As variáveis podem ser múltiplas, de acordo com as informações que se tem ou que parecem ser úteis para o que se pretende observar em cada grupo, em determinado tempo e contexto. Outra vantagem da metodologia é pensar no perfil mais frequente como aquele composto por indivíduos que possuem as características dominantes em dada amostra, tempo e dimensão, ou seja, os grupos sub-representados ou vulneráveis não são definidos à priori, mas a partir de sua representatividade na amostra e no universo mais amplo.

Vejamos, então, os resultados gerados pelo uso desta metodologia para identificar o pefil do alunado beneficiário do $\mathrm{CsF}$ e de outros programas de mobilidade internacional implementados pela Unicamp no período de vigência e após o término do programa.

\section{Perfil interseccional dos beneficiários do CsF e de outros programas de mobilidade internacional na Unicamp}

A partir da aplicação da metodologia interseccional desenvolvida para analisar o perfil dos beneficiários dos programas de mobilidade internacional na graduação, podemos compreender melhor os conceitos apresentados. Combinando cinco categorias/variáveis como definidoras do conceito de perfil interseccional no âmbito do presente trabalho, os dados dos 1.440 alunos de graduação da Unicamp contemplados com bolsas do $\mathrm{CsF}^{14}$ foram agrupados,

${ }^{14}$ Os dados foram fornecidos pela Diretoria Acadêmica da Unicamp (DAC). 
automaticamente pelo software AIP, em 58 perfis diferentes. Dentre eles, 11 perfis aparecem como mais frequentes, como se pode observar no Quadro 3.

O perfil mais frequente de bolsista do CsF na Unicamp foi o masculino, branco, sem necessidades especiais, não beneficiário do PAAIS e oriundo de escola particular no ensino médio, representando $31 \%$ do total de bolsistas do CsF. O segundo perfil mais frequente $(25,9 \%)$, foi o feminino com o restante de características idênticas ao primeiro grupo. Desta forma, estudantes de cor branca, sem necessidades especiais, que não utilizaram o PAAIS e oriundos de escola particular representaram cerca de $57 \%$ do total de bolsas CsF concedidas à graduação da Unicamp.

Quadro 3 - Perfis mais frequentes dos beneficiários do CsF (2012-2016)

\begin{tabular}{|r|c|c|c|c|c|c|}
\hline \multicolumn{1}{|c|}{ Qtde } & \multicolumn{1}{c|}{$\%$} & Sexo & Cor/raça & $\begin{array}{c}\text { Necessidades } \\
\text { Especiais }\end{array}$ & $\begin{array}{c}\text { Benefício } \\
\text { PAAIS }\end{array}$ & Natureza Ensino Médio \\
\hline 447 & 31,04 & M & Branca & Não & Não & 2 grau Particular \\
\hline 373 & 25,90 & F & Branca & Não & Não & 2 grau Particular \\
\hline 87 & 6,40 & M & Branca & Não & Sim & 2 grau Técnico Público \\
\hline 54 & 3,75 & F & Branca & Não & Sim & 2 grau Técnico Público \\
\hline 53 & 3,68 & M & Branca & Não & Sim & 2 grau Público \\
\hline 51 & 3,54 & M & Amarela & Não & Não & 2 grau Particular \\
\hline 49 & 3,40 & F & Amarela & Não & Não & 2 grau Particular \\
\hline 40 & 2,78 & M & Parda & Não & Não & 2 grau Particular \\
\hline 31 & 2,15 & M & Branca & Não & Não & 2 grau Público \\
\hline 29 & 2,01 & F & Branca & Não & Sim & 2 grau Público \\
\hline 29 & 2,01 & F & Parda & Não & Não & 2 grau Particular \\
\hline
\end{tabular}

Ao analisarmos a variável cor/raça isoladamente, enquanto os alunos pardos e pretos representavam, na média do período, 16,68\% dos matriculados (Quadro 1), eles foram apenas 9,38\% dos bolsistas contemplados pelo $\mathrm{CsF}^{15}$. Em contraponto, alunos de cor/raça amarela, tiveram uma participação maior no $\mathrm{CsF}$ do que sua representação entre os matriculados na Unicamp no mesmo período (5\% dos matriculados da Unicamp, mas $8 \%$ dos bolsistas CsF). O mesmo ocorre quando observamos a participação de alunos no programa segundo sua escola de origem no ensino médio: alunos oriundos exclusivamente do ensino médio público ${ }^{16}$, entre 2012 e 2016, representavam 35\% das matrículas, mas apenas 25\% dos bolsistas CsF; enquanto

\footnotetext{
15 Alunos autoidentificados como de cor preta representavam 3,5\% dos matriculados no período, enquanto eles foram apenas $1,1 \%$ (17 alunos) dos beneficiários do CsF na Unicamp.

${ }^{16}$ Foram excluídos nesta análise os alunos que fizeram o ensino médio parcialmente em escola pública e privada ou que realizaram o ensino médio no exterior.
} 
aqueles oriundos exclusivamente de escola particular representavam em média 57,6\% das matrículas da Unicamp no período, mas conquistaram cerca de $71 \%$ das bolsas CsF da universidade. Considerando os alunos com necessidades especiais, o CsF não teve nenhum aluno desse grupo como bolsista. No período do estudo, a Unicamp teve apenas 47 alunos matriculados com necessidades especiais $(0,28 \%)$, o que demonstra que as barreiras para esses alunos se impõem principalmente no acesso à universidade.

Quando analisamos sob a ótica do perfil interseccional, revelam-se outras desigualdades mais sensíveis. O primeiro perfil de alunos de cor preta mais frequente no CsF (com 6 alunos (0,42\% do total), $21^{\circ}$ posição dentre os 55 perfis de beneficiários) é o masculino, sem necessidades especiais, não beneficiário do PAAIS e oriundos de escola particular. Assim, exceto a variável cor/raça, o perfil do aluno preto mais frequente conserva as outras características dominantes do "perfil ideal” branco, quais sejam, masculino, sem necessidades especiais, sem benefício do PAAIS, e oriundos de escola particular. Claramente, o aluno de cor preta com mais chance é aquele que teve mais oportunidades no decorrer da vida.

O segundo e o terceiro perfil mais frequente de aluno preto, com 4 alunos $(0,28 \%$ do total de beneficiários) e 3 alunos $(0,21 \%)$, também são conformados por estudantes do sexo masculino, todos sem necessidades especiais, alterando o tipo de escola (público e técnico público) e a bonificação do PAAIS (ambos tiveram aumento de notas pelo programa). Mulheres da cor preta, beneficiárias do $\mathrm{CsF}$ são apenas 3 no total, desagregadas em 3 perfis diferentes (uma delas em cada perfil, empatadas nas últimas posições da lista de perfis com $0,07 \%$ do total ${ }^{17}$ ). Outro caso a ser analisado é o dos indígenas em que apenas 1 aluno desse grupo foi bolsista CsF, sendo este do sexo masculino, sem necessidades especiais, não bolsista do PAAIS e oriundo de escola particular. Deste modo, não basta analisarmos isoladamente quantas mulheres, ou quantos pretos, pardos ou indígenas foram contemplados pelo programa, mas sim, “quais" mulheres, "quais" pretos, pardos ou indígenas e em quais condições. Mesmo que o alunado da Unicamp no mesmo período do programa tenha se diversificado, isso não se refletiu nas mesmas oportunidades de mobilidade internacional.

Neste sentido, os perfis menos frequentes de alunos bolsistas do $\mathrm{CsF}$ foram aqueles que mais se afastaram do perfil com características dominantes, ou seja, quanto mais variáveis

\footnotetext{
${ }^{17}$ Os três perfis de mulheres negras eram todas sem necessidades especiais, duas delas tiveram auxílio do PAAIS e uma não, e sobre a natureza do Ensino médio, uma delas estudou em escola particular, outra em técnico público e uma em ensino público regular.
} 
diferentes do "perfil ideal", menos indivíduos apareciam como contemplados pelas bolsas, revelando quem eram os grupos vulneráveis e sub-representados.

Ao compararmos com o perfil interseccional dos beneficiários de outros programas de mobilidade internacional (convênios de duplo diploma ou para cursar disciplinas isoladas no exterior) na universidade no mesmo período do CsF, notamos que o "perfil ideal" se mantém, exceto pela questão de gênero (Quadro 4).

Quadro 4 - Perfil dos alunos beneficiados por outros programas de mobilidade internacional, entre 20122016

\begin{tabular}{|r|c|c|c|c|c|c|}
\hline Total & \multicolumn{1}{|c|}{$\%$} & Sexo & Cor/Raça & $\begin{array}{c}\text { Necessidades } \\
\text { Especiais }\end{array}$ & PAAIS & Natureza Ensino Médio \\
\hline 124 & 28,57 & $\mathrm{~F}$ & Branca & Não & Não & 2 grau Particular \\
\hline 98 & 22,58 & $\mathrm{M}$ & Branca & Não & Não & 2 grau Particular \\
\hline 26 & 5,991 & $\mathrm{~F}$ & Branca & Não & Sim & 2 grau Público \\
\hline 23 & 5,3 & $\mathrm{~F}$ & Branca & Não & Sim & 2 grau Técnico Público \\
\hline 18 & 4,147 & $\mathrm{M}$ & Branca & Não & Sim & 2 grau Técnico Público \\
\hline 11 & 2,535 & $\mathrm{M}$ & Branca & Não & Não & 2 grau Público \\
\hline 10 & 2,304 & $\mathrm{M}$ & Parda & Não & Sim & 2 grau Público \\
\hline 9 & 2,074 & $\mathrm{~F}$ & Parda & Não & Não & 2 grau Particular \\
\hline
\end{tabular}

Analisando as variáveis a partir da perspectiva interseccional, podemos agregar os 434 bolsistas em 55 diferentes perfis. O Quadro 4 apresenta os perfis mais frequentes, que concentram mais de $70 \%$ do total de bolsistas. Diferentemente do CsF, há uma predominância de mulheres beneficiárias, com 52,62\% do total de bolsas de mobilidade internacional concedidas entre 2012-2016.

A maior presença feminina ${ }^{18}$ pode ser explicada pelo fato de que grande parte dos beneficiários das bolsas foram alunos oriundos de cursos de artes e humanidades (excluídos pelo CsF), cursos que, tradicionalmente, têm mais alunas do que alunos. Por exemplo, o curso com maior número de contemplados nesse período foi o de ciências econômicas (com 51 alunos contemplados, $11,75 \%$ do total), seguido de ciências sociais (44 alunos, 10,14\% do total) e, posteriormente, gestão de comércio internacional (26 alunos, 5,99\%).

Além disso, o fato de que, no mesmo período, estavam sendo concedidas bolsas de mobilidade pelo CsF voltadas às áreas tecnológicas e exatas em geral, pode ter diminuído o interesse de alunos oriundos desses cursos (com predominância masculina). Considerando a

\footnotetext{
${ }^{18}$ As mulheres foram 56,68\% do total de beneficiárias dos outros programas de mobilidade no período de 2012 a 2016, contra 43,19\% do total de beneficiárias do CsF.
} 
participação de mulheres apenas nos cursos que tiveram bolsistas do CsF, observamos que menos de $40 \%$ do alunado destes cursos era formado por mulheres (FELTRIN; COSTA; VELHO, 2016).

Assim, levando em conta que essas bolsas eram abertas a todos os cursos de graduação, as mulheres, brancas, sem necessidades especiais, que não utilizaram recursos do PAAIS para o ingresso na universidade e eram oriundas de instituições particulares no ensino médio, compunham o perfil mais frequente entre os bolsistas de outros programas de mobilidade internacional na instituição, com 124 alunos com as mesmas características (28,57\% do total). Analisando o perfil destas bolsistas, algumas questões interessantes e sensíveis desse grupo começam a aparecer. Por exemplo, mesmo que as mulheres sejam mais numerosas que os homens como bolsistas, o primeiro perfil mais frequente em que aparece um não-branco é formado por homens (composto por 10 alunos, 2,30\% do total). As mulheres pardas aparecem logo em seguida, entretanto, são mulheres oriundas do ensino médio particular (composto por 9 alunas, 2,07\% do total), diferentemente dos homens pardos que as antecedem na lista. Só para efeito de comparação, mulheres pardas oriundas de escolas públicas aparecem somente 5 posições abaixo (composto por 5 alunas, $1,15 \%$ do total).

Vale apontar que entre os bolsistas de outros programas de mobilidade aparecem duas alunas com necessidades especiais $(0,46 \%$ do total de bolsistas). Ambas são do sexo feminino, brancas e não foram beneficiárias do PAAIS. Uma delas cursou escola particular no ensino médio e outra, uma escola pública no exterior (no país de seu nascimento). As duas alunas eram de cursos da área de humanidades da Unicamp. O fato dos únicos alunos participantes com necessidades especiais nesse período serem duas mulheres brancas de origem socioeconômica mais elevada (já que até a aluna de escola pública não se enquadrava nos critérios de renda do PAAIS), nos leva a refletir que tal condição não foi impeditiva para participarem do programa, fato que pode ser explicado por conta de suas outras características "dominantes" que permitiram equilibrar suas oportunidades frente aos outros. O mesmo ocorreu no caso dos indígenas que, assim como no $\mathrm{CsF}$, teve apenas um aluno representante desse grupo selecionado - em ambos os casos, os alunos possuíam exatamente o mesmo perfil: masculino, não beneficiário do PAAIS, sem necessidades especiais e oriundo de escola particular.

Quando consideramos sexo e classe no contexto dos bolsistas de mobilidade fora do $\mathrm{CsF}$, o perfil mais frequente em que aparece ensino público é composto por mulheres brancas (26 alunas, representando 5,99\% do total). Os homens, em situação equivalente aparecem 3 posições abaixo, com 11 alunos, 2,53\% do total). Ou seja, os homens parecem sofrer menos as 
dificuldades sociais impostas pelas desigualdades de cor/raça do que daquelas ligadas à classe social.

No estudo desenvolvido por Feltrin, Costa e Velho (2016), baseando-se nas respostas qualitativas dos questionários aplicados aos ex-bolsistas do $\mathrm{CsF}$, foi observado que a origem da escola de ensino médio teve um impacto significativo sobre as experiências de vida e expectativas de carreira entre os homens participantes do programa. $\mathrm{O}$ mesmo não ocorreu no caso das mulheres, tendo em vista que outros indicadores de acesso ao capital cultural (conhecimento prévio do idioma, viagens prévias ao exterior, etc.) permaneceram praticamente inalterados entre as estudantes que cursaram escola privada ou pública no ensino médio. Tal dado parece nos indicar que, para terem acesso às mesmas oportunidades que os homens, as mulheres precisam ter tido experiências prévias extras no decorrer da vida (FELTRIN; COSTA; VELHO, 2016).

Outro importante achado do estudo esteve ligado à questão do 'planejamento de participação em programa de mobilidade internacional' por parte dos ex-bolsistas, revelando que a maioria das mulheres e dos homens oriundos de escola pública não apresentava intenção de participar de programas de mobilidade internacional antes de conhecerem o $\mathrm{CsF}$, sugerindo que o programa foi um fator determinante na possibilidade de experiência de mobilidade internacional desses bolsistas na Unicamp (FELTRIN; COSTA; VELHO, 2016).

As oportunidades de bolsas de mobilidade internacional da Unicamp, sejam do CsF ou de outros programas, no período, foram direcionadas para dois perfis mais frequentes: ambos de alunos brancos, sem necessidades especiais, não bonificados pelo PAAIS e oriundos de escola particular, que concentraram mais da metade dos beneficiários: $51,15 \%$ do total no caso das bolsas de mobilidade internacional concedidas por outros programas no mesmo período do CsF e uma concentração ainda maior desses perfis no CsF, com $57 \%$ do total.

Após o término do CsF, entre fevereiro de 2016 e abril de 2018, os alunos oriundos de cursos antes contemplados pelo programa voltaram a concorrer às vagas nos outros programas de mobilidade. Os cursos considerados prioritários pelo CsF passaram a figurar entre aqueles com maior número de bolsas de mobilidade internacional, como por exemplo, Engenharia Mecânica, em primeiro lugar com 11,06\% do total de bolsas e Engenharia Elétrica, em terceiro lugar com $6,72 \%$ das bolsas.

Nesse momento, o "perfil dominante" voltou a ser composto por homens, brancos, sem necessidades especiais e sem bonificação do PAAIS, e as mulheres voltaram a ser subrepresentadas (exatamente como ocorreu no $\mathrm{CsF}$ ), conforme Quadro 5. As outras características do perfil dominante também se mantiveram - brancos, sem necessidades especiais, não 
beneficiários do PAAIS e oriundos de escolas de ensino médio particulares. Neste período, não houve nenhum aluno com necessidades especiais participante de programas de mobilidade na instituição.

Quadro 5 - Perfil dos alunos beneficiados por outros programas de mobilidade internacional, após término do CsF (fevereiro de 2016 a abril de 2018)

\begin{tabular}{|r|r|c|c|c|c|c|}
\hline TOTAL & \multicolumn{1}{|c|}{$\%$} & SEXO & Cor/RAÇA & $\begin{array}{c}\text { Especsidades } \\
\text { Especiais }\end{array}$ & PAAIS & NATUREZA 2 GRAU \\
\hline 94 & 20,39 & M & Branca & Não & Não & 2 grau Particular \\
\hline 81 & 17,57 & F & Branca & Não & Não & 2 grau Particular \\
\hline 37 & 8,02 & M & Branca & Não & Não & n/d* \\
\hline 37 & 8,02 & F & Branca & Não & Não & n/d \\
\hline 19 & 4,12 & M & Branca & Não & Sim & 2 grau Técnico Público \\
\hline 15 & 3,25 & F & Branca & Não & Sim & 2 grau Técnico Público \\
\hline 14 & 3,03 & M & Branca & Não & Sim & n/d \\
\hline 12 & 2,60 & M & Branca & Não & Não & grau Público \\
\hline 11 & 2,38 & F & Parda & Não & Não & n/d \\
\hline 10 & 2,16 & F & Amarela & Não & Não & grau Particular \\
\hline 9 & 1,95 & F & Branca & Não & Não & 2 grau Público \\
\hline 9 & 1,95 & M & Branca & Não & Sim & 2 grau Público \\
\hline
\end{tabular}

* n/d = não declarada

Em suma, os resultados indicam que apensar de contemplar características que poderiam favorecer a inclusão social, o CsF teve um impacto pequeno na ampliação do capital cultural dos alunos de classes sociais mais baixas através da experiência da mobilidade internacional. O CsF continuou atendendo a um perfil específico de aluno, que já era beneficiado pelos outros programas de mobilidade internacional.

\section{Considerações finais}

A pesquisa buscou contribuir para a geração de evidências sobre o papel do CsF na inclusão social de estudantes da Unicamp. Através da análise do perfil dos alunos de forma interseccional, foi possível identificar algumas nuances e complexidades relacionadas aos grupos beneficiados pelo programa que não poderiam ser captadas pela análise segmentada das variáveis.

Dadas as características do CsF, era esperado que a distribuição de bolsas de mobilidade internacional ocorresse de forma mais inclusiva e convergente com a distribuição da diversidade de perfis socioeconômicos que compõem o alunado da Unicamp. No entanto, ao analisarmos os perfis interseccionais dos beneficiários do $\mathrm{CsF}$, dos beneficiários de outros 
programas de mobilidade internacional da Unicamp e compararmos com os dados sobre o alunado da universidade no mesmo período, percebemos que a inclusão social de alunos da Unicamp através do CsF não se efetivou na prática. Pelo contrário, o CsF quando comparado aos outros programas de mobilidade internacional disponíveis no mesmo período e após o término do programa, mostrou uma concentração maior no perfil "ideal" de aluno, branco, sem necessidades especiais, sem bonificação do PAAIS e oriundo de escola privada. Obviamente, para uma análise mais detalhada, seria preciso conhecer também o perfil dos alunos que se inscreveram no programa para comparar com os que de fato foram selecionados, analisar os perfis de alunos divididos por curso e ainda, realizar um estudo qualitativo para captar as nuances e as particularidades dos perfis analisados. Entretanto, seja por uma possível seleção reduzida de alunos oriundos de classes sociais mais baixas ou mesmo pelo possível fato de que esses alunos nem tenham chegado a se inscrever no programa, a situação apresentada nos dá indícios de que as oportunidades extras no decorrer da vida têm um peso significativo no acesso às oportunidades também durante a graduação e, possivelmente, na carreira desses alunos.

Devemos ainda considerar que, mesmo que esses alunos de baixa renda estejam ingressando mais facilmente na IES, eles podem não estar se sentindo autorizados a participarem de determinadas oportunidades que surgem no interior da universidade, como é o caso da mobilidade internacional. Talvez muitos deles sequer tenham se inscrito por não poderem se ausentar do país, seja por contribuírem para a composição da renda familiar, por serem cuidadores de outros membros da família ou, simplesmente, por não considerarem o programa como uma oportunidade real para sua vida ${ }^{19}$. Nesse sentido, apenas a democratização do acesso à universidade e a consequente mudança na composição do perfil universitário podem não estar sendo suficientes para que mudanças estruturais no interior da universidade se efetivem. Para que esses alunos não continuem participando marginalmente do sistema universitário ou acabem assimilando acriticamente valores que contribuem para a reprodução de opressões sociais, é preciso pensar em ações que estimulem esses alunos a ocuparem novos espaços dentro da instituição, para que consigam transformar a universidade e a própria realidade social sem que tenham que renunciar a si próprios.

A metodologia criada para a operacionalização das variáveis (através do conceito de perfil interseccional), se mostrou uma ferramenta útil não somente por contribuir para o debate teórico/acadêmico sobre como se constituem e se perpetuam as desigualdades sociais, mas

${ }^{19}$ Agradecemos às(os) revisoras (es) pela sugestão destes possíveis fatores. 
também se mostrou relevante no campo da intervenção política. Além de oferecer subsídios para que as IES possam otimizar seus processos de seleção de bolsistas de mobilidade estudantil, a metodologia pode auxiliar os gestores de políticas públicas no desenvolvimento de ações, programas ou estratégias mais amplas para a inclusão social dos mais variados grupos e contextos.

\section{Referências}

ALMEIDA, Ana Maria F.; ERNICA, Maurício. Inclusão e segmentação social no Ensino Superior público no Estado de São Paulo (1990-2012). Educação \& Sociedade [online], Campinas, v. 36, n. 130, p. 63-83, 2015. Disponível em:

https://www.scielo.br/scielo.php?pid=S0101-

73302015000100063\&script=sci_abstract\&tlng=pt. Acesso em: 18 fev. 2020.

BARBOSA, Carla Maria Palmeira Soares. Impacto do capital cultural na mobilidade social: o caso das escolas profissionais de música. 2016. Tese (Doutorado) - Universidade de Barcelona, Barcelona, 2016.

BOURDIEU, Pierre. A distinção: crítica social do julgamento. São Paulo: Edusp; Porto Alegre, RS: Zouk, 2007.

BOURDIEU, Pierre; PASSERON, Jean-Claude. A reprodução. Elementos para uma teoria do sistema de ensino. Rio de Janeiro: Francisco Alves, 1975.

BRASIL. Relatório Educação para Todos no Brasil 2000-2015. Brasília: INEP, 2015. Disponível em: http://portal.mec.gov.br/docman/junho-2014-pdf/15774-ept-relatorio06062014. Acesso em: 22 jan. 2020.

CRENSHAW, Kimberlé. Documento para o encontro de especialistas em aspectos da discriminação racial relativos ao gênero. Revista de Estudos Feministas, Florianópolis, v. 7, n. 12, p. 171-188, 2002.

CHO, Sumi et al. Toward a field of intersectionality studies: theory, applications, and praxis. Signs: Journal of Women in Culture and Society, Chicago, v. 38, n. 4, p. 785-810, 2013.

DIMAGGIO, Paul. Cultural capital and school success: the impact of status culture participation on the grades of U.S. High School Students. American Sociological Review, Washington, v. 47, n. 2, p. 189-201, 1982.

FELTRIN, Rebeca Buzzo; COSTA, Janaína Oliveira Pamplona; VELHO, Lea. Mulheres sem fronteiras? Uma análise da participação das mulheres no Programa Ciência sem Fronteiras da Unicamp: motivações, desafios e impactos na trajetória profissional. Cadernos Pagu, Campinas, n. 48, e164804, 2016.

HIRATA, Helena. Gênero, Casse e raça. Interseccionalidade e consubstancialidade das relações sociais. Tempo Social, revista de sociologia da USP, São Paulo, v. 26, n. 1, p. 6173, 2014. 
JUNQUEIRA, Rogério Diniz. Prefácio. In: LOPES, Maria Auxiliadora; BRAGA, Maria Lúcia de Santana (orgs.). Acesso e permanência da população negra no ensino superior. Brasília: Ministério da Educação, Secretaria de Educação Continuada, Alfabetização e Diversidade; Unesco, 2007.

KERGOAT, Danièle. Dinâmica e consubstancialidade das relações sociais. Novos estudos CEBRAP, São Paulo, n. 86, p. 93-103, 2010.

KHOMYAKOV, Maxim et al. Internacionalização da educação superior: excelência ou construção de redes? Do que os países do BRICS precisam mais? Sociologias, Porto Alegre, v. 22, n. 54, p. 120-143, maio/ago. 2020.

LEE, M. Talvez eu não esteja em ascensão social, talvez esteja questionando as hierarquias de classe": jovens pobres na universidade e a sobrevivência sob a hierarquia. E-cadernos CES [Online], Coimbra, n. 18, 2012, Disponível em: http://eces.revues.org/1536. Acesso em: 12 fev. 2020.

McCALL, Leslie. The complexity of intersectionality. Signs: Journal of Women in Culture and Society, Chicago, v. 30, n. 3, p. 1771-1800, 2005.

MOREIRA, Gláucia de Oliveira et al. Inclusão social e ações afirmativas no ensino superior no Brasil: para quê? Revista Ensino Superior Unicamp [online], Campinas, 2017.

Disponível em: https://www.revistaensinosuperior.gr.unicamp.br/artigos/inclusao-social-eacoes-afirmativas-no-ensino-superior-no-brasil-para-queij. Acesso em: 21 fev. 2020.

MOUTINHO, Laura. Diferenças e desigualdades negociadas: raça, sexualidade e gênero em produções acadêmicas recentes. Cadernos Pagu, Campinas, n. 42, p. 201-248, 2014.

NEVES, Clarissa Eckert Baeta; BARBOSA, Maria Lígia de Oliveira. Internacionalização da educação superior no Brasil: avanços, obstáculos e desafios. Sociologias, Porto Alegre, ano 22, n. 54, p. 144-175, maio/ago. 2020.

RISTOFF, Dilvo. O novo perfil do campus brasileiro: uma análise do perfil socioeconômico do estudante de graduação. Avaliação, Campinas; Sorocaba, SP, v. 19, n. 3, p. 723-747, nov. 2014. Disponível em: https://www.scielo.br/scielo.php?pid=S1414-

40772014000300010\&script=sci_abstract\&tlng=pt. Acesso em: 12 fev. 2020.

RISTOFF, Dilvo. Democratização do campus: impacto dos programas de inclusão sobre o perfil da graduação. Cadernos do GEA, Rio de Janeiro, n. 9, jan./jun. 2016.

SAVIANI, Demerval. Escola e democracia. Edição Comemorativa. Campinas: Autores Associados, 2008.

SCHWARTZMAN, Simon. A crise da universidade. Revista Ensino Superior, Campinas, n. 10, jul./set. 2013.

SEABRA, Teresa. Desigualdades escolares e desigualdades sociais. Sociologia, Problemas e Práticas [online], Lisboa, n. 59, p.75-106, 2009. Disponível em: https://sociologiapp.iscteiul.pt/pdfs/10120/10123.pdf. Acesso em: 14 abr. 2020. 
UNICAMP. Universidade Estadual de Campinas. A Unicamp em 2013-2017. Relatório de atividades. Campinas: Unicamp, 2017. Disponível em:

https://www.unicamp.br/unicamp/sites/default/files/2017-04/RELATORIO_GESTAO_201317_TJ_WEB_170425_03.pdf. Acesso em: 29 abr. 2020.

UUKI. Universities UK Internacional. Gone International: expanding opportunities. Report on the 2015-16 graduating cohort. 2018.

VELHO, Lea et al. Avaliação de impacto do Programa Ciência Sem Fronteiras: proposta metodológica. Brasília: CGEE, 2013. [Trabalho técnico]. 